\section{The Tautomeric Conformers for the Molecules of Guanine and Cytosine. Some Remarks about Their Stability}

\author{
Julio Marañon * and Oscar M. Sorarrain * \\ Departamentos de Física y Química, \\ Facultad de Ciencias Exactas,
}

Universidad Nacional de La Plata, La Plata, Argentina

\author{
(Z. Naturforsch. 32 c, 870-873 [1977] ; received \\ May 4,1977 ) \\ Tautomeric, Barriers, Singlets, Triblets
}

In this paper we seek to determine the shape of the barrier between the normal and tautomeric conformers for some excited singlet and triplet states in the molecules of guanine and cytosine. The molecules are considered isolated and a particular movement of the $\mathrm{H}$ atom is analysed.

The semi-empirical CNDO/2-CI has been used. The calculated results are compared with the available experimental data.

\section{Introduction}

The stability of the different tautomeric species involved in the DNA is an interesting biological problem. The molecules of adenine, thymine, guanine and cytosine has been analysed experimental and theoretically in many papers ${ }^{1-11}$. Now we shall be concerned with the isolated molecules of guanine and cytosine, that is, we seek to determine the shape of the barrier between their conformers for a particular movement as another point of view for a theoretical analysis of the relative stability for the normal and tautomeric forms in both mole-

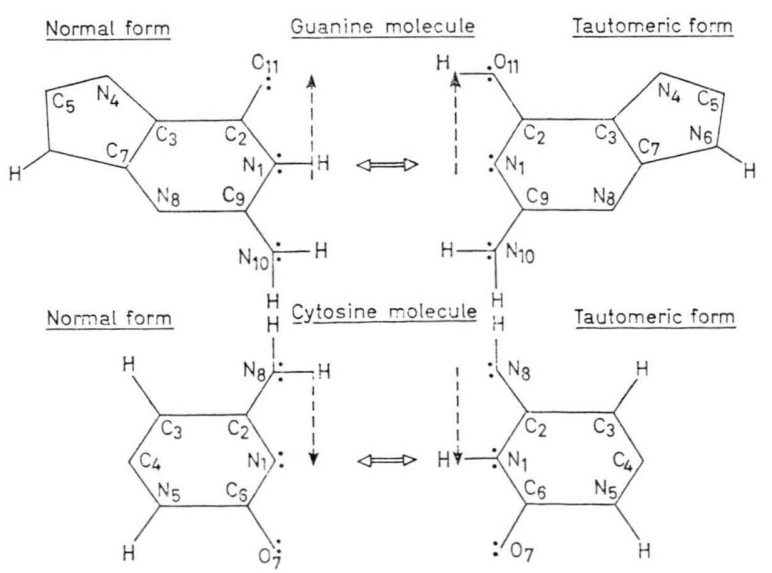

Fig. 1. The normal and tautomeric conformations. Molecules of guanine and cytosine.

* Miembros de Carrera del Investigador Conicet. cules. These molecules has been extensively considered with theoretical and experimental techniques ${ }^{12-18}$ and many interesting results has been reported but there is no mention for the barrier corresponding to the movement of the $\mathrm{H}$ atom in the way shown in Fig. 1.

This movement is certainly a criterion for the stability. The shape of the barriers for several excited states shall be given in this paper.

\section{Employed method and results}

The calculation of the barrier for the proton transfer between both conformers have been undertaken using a CNDO/2-CI program (174 QCPEIndiana University). Several single excited singlet

Table I. Singlet and triplet states-molecule of guanine.

Table I a.

\begin{tabular}{|c|c|c|c|c|c|}
\hline \multicolumn{6}{|c|}{ Guanine } \\
\hline \multicolumn{3}{|c|}{ Normal } & \multicolumn{3}{|c|}{ Tautomeric } \\
\hline M.O. & Type & Localization & M.O. & Type & Localization \\
\hline 25 & $\pi$ & delocalized & $\leftrightarrow 26$ & $\pi$ & $\mathrm{N}_{1}(0.48)$ \\
\hline 26 & $\mathrm{n}(\sigma)$ & $\mathrm{O}_{11}(0.70)$ & $\leftrightarrow 25$ & $\mathrm{n}(\sigma)$ & $\mathrm{N}_{1}(0.52)$ \\
\hline 27 & $\sigma$ & $\mathrm{C}_{8}(0.40)$ & $\leftrightarrow 27$ & $\sigma$ & $\mathrm{C}_{8}(0.50)$ \\
\hline 28 & $\pi$ & delocalized & $\leftrightarrow 28$ & $\pi$ & delocalized \\
\hline
\end{tabular}

Table I b.

\begin{tabular}{|c|c|c|c|c|c|}
\hline \multicolumn{6}{|c|}{ Excited Singlets } \\
\hline & \multicolumn{2}{|l|}{ Normal } & \multirow{2}{*}{$\begin{array}{l}\text { Experi- } \\
\text { mental } \\
{[\mathrm{eV}]}\end{array}$} & \multicolumn{2}{|l|}{ Tautomeric } \\
\hline & $\begin{array}{l}\text { Energy } \\
{[\mathrm{eV}]}\end{array}$ & Type & & $\begin{array}{l}\text { Energy } \\
{[\mathrm{eV}]}\end{array}$ & Type \\
\hline \multirow{5}{*}{$\begin{array}{l}\text { lst } \\
\text { region }\end{array}$} & 2.8 & $\sigma-\pi^{*}$ & & 2.78 & $\sigma-\pi^{*}$ \\
\hline & 3.37 & $\sigma-\pi^{*}$ & & 3.32 & $\sigma-\pi^{*}$ \\
\hline & $3.75(0.17)$ & $\sigma-\pi^{*}$ & & 3.69 & $\sigma-\pi^{*}$ \\
\hline & 3.81 & $\pi-\pi^{*}$ & & $4.07(0.03)$ & $\pi-\pi^{*}$ \\
\hline & $4.59(0.15)$ & $\sigma-\pi^{*}$ & 4.5 & $4.54(0.20)$ & $\sigma-\pi^{*}$ \\
\hline \multirow[t]{2}{*}{$\begin{array}{l}\text { 2nd } \\
\text { region }\end{array}$} & $5.06(0.13)$ & $\sigma-\pi^{*}$ & 4.8 & $5.36(0.10)$ & $\sigma-\pi^{*}$ \\
\hline & \multicolumn{5}{|c|}{ Oscillator strength () . } \\
\hline \multicolumn{6}{|c|}{ Excited triplets } \\
\hline & \multicolumn{2}{|l|}{ Normal } & \multirow{2}{*}{$\begin{array}{l}\text { Experi- } \\
\text { mental } \\
{[\mathrm{eV}]}\end{array}$} & \multicolumn{2}{|l|}{ Tautomeric } \\
\hline & $\begin{array}{l}\text { Energy } \\
{[\mathrm{eV}]}\end{array}$ & Type & & $\begin{array}{l}\text { Energy } \\
{[\mathrm{eV}]}\end{array}$ & Type \\
\hline & 2.07 & $\pi-\pi^{*}$ & & 2.30 & $\pi-\pi^{*}$ \\
\hline & 2.58 & $\sigma-\pi^{*}$ & & 2.78 & $\sigma-\pi^{*}$ \\
\hline & 2.81 & $\sigma-\pi^{*}$ & & 3.22 & $\sigma-\pi^{*}$ \\
\hline & 3.08 & $\pi-\pi^{*}$ & 3.2 & 3.32 & $\pi-\pi^{*}$ \\
\hline & 3.37 & $\pi-\pi^{*}$ & & 3.37 & $\pi-\pi^{*}$ \\
\hline
\end{tabular}


and triplet electronic states have been considered. The molecular parameters (bond angles and interatomic distances) for both molecules are the same values reported in standard tables ${ }^{20}$. We have taken 30 configurations with a $0.2 \AA$ mash for the movement of the $\mathrm{H}$ atom. The relative position of the $\mathrm{H}$ in both conformations, normal and tautomeric is shown in Fig. 1.

In the molecule of guanine we have determined the correlations between both molecular forms. There are some differences in the order of the higher occupied molecular orbitals interesting enough to be pointed out. These orbitals should be involved in the observed electronic transitions (see Table I a).

In Table I b we have followed the spectral classification given by former authors ${ }^{3,9}$ for the experimental singlet lines. The triplet states are also given in the same table.

The agreement between the available experimental measures and the values predicted in this paper is really satisfactory. The barriers for some $\sigma-\pi^{*}$

Table II. Singlet and triplet states-molecule of cytosine.

Table II a.

\begin{tabular}{|c|c|c|c|c|c|}
\hline \multicolumn{6}{|c|}{ Cytosine } \\
\hline \multicolumn{3}{|c|}{ Normal } & \multicolumn{3}{|c|}{ Tautomeric } \\
\hline M.O. & Type & Localization & M.O. & Type & Localization \\
\hline 18 & $\mathrm{n}(\sigma)$ & $\mathrm{N}_{1}(0.64)$ & 18 & $\mathrm{n}(\sigma)$ & $\mathrm{O}_{7}(0.62)$ \\
\hline 19 & $\pi$ & delocalized & 20 & $\pi$ & delocalized \\
\hline 20 & $\mathrm{n}(\sigma)$ & $\mathrm{O}_{7}(0.54)$ & 19 & $\sigma$ & $\mathrm{N}_{8}(0.49)$ \\
\hline 21 & $\pi$ & $\mathrm{N}_{1}(0.32)$ & 21 & $\pi$ & $\mathrm{N}_{8}(0.38)$ \\
\hline
\end{tabular}

Table II b.

\begin{tabular}{|c|c|c|c|c|c|}
\hline \multicolumn{6}{|c|}{ Excited singlets } \\
\hline & \multicolumn{2}{|l|}{ Normal } & \multirow{2}{*}{$\begin{array}{l}\text { Experi- } \\
\text { mental } \\
{[\mathrm{eV}]}\end{array}$} & \multicolumn{2}{|l|}{ Tautomeric } \\
\hline & $\begin{array}{l}\text { Energy } \\
{[\mathrm{eV}]}\end{array}$ & Type & & $\begin{array}{l}\text { Energy } \\
{[\mathrm{eV}]}\end{array}$ & Type \\
\hline & 3.39 & \multicolumn{2}{|l|}{$\sigma-\pi^{*}$} & 3.5 & $\sigma-\pi^{*}$ \\
\hline & $4.10(0.11)$ & \multicolumn{2}{|l|}{$\pi-\pi^{*}$} & 4.49 & $\pi-\pi^{*}$ \\
\hline \multirow{2}{*}{ region } & 4.17 & $\pi-\pi^{*}$ & \multirow{2}{*}{\multicolumn{3}{|c|}{$\pi-\pi^{*}$}} \\
\hline & 4.75 & $\sigma-\pi^{*}$ & & & \\
\hline \multirow[t]{2}{*}{$\begin{array}{l}\text { 2nd } \\
\text { region }\end{array}$} & $5.43(0.01)$ & $\pi-\pi^{*}$ & 5.2 & 5.02 & $\sigma-\pi^{*}$ \\
\hline & \multicolumn{3}{|c|}{ Oscillator strength (). } & $5.53(0.02)$ & $\pi-\pi^{*}$ \\
\hline \multicolumn{6}{|c|}{ Excited triplets } \\
\hline & \multicolumn{2}{|l|}{ Normal } & \multirow{2}{*}{$\begin{array}{l}\text { Experi- } \\
\text { mental } \\
{[\mathrm{eV}]}\end{array}$} & \multicolumn{2}{|l|}{ Tautomeric } \\
\hline & $\begin{array}{l}\text { Energy } \\
{[\mathrm{eV}]}\end{array}$ & Type & & $\begin{array}{l}\text { Energy } \\
{[\mathrm{eV}]}\end{array}$ & Type \\
\hline & 1.90 & $\pi-\pi^{*}$ & & 1.41 & $\pi-\pi^{*}$ \\
\hline & 3.22 & $\sigma-\pi^{*}$ & 3.1 & 2.72 & $\sigma-\pi^{*}$ \\
\hline & 3.59 & $\sigma-\pi^{*}$ & & 3.35 & $\sigma-\pi^{*}$ \\
\hline & 4.17 & $\pi-\pi^{*}$ & & 4.49 & $\pi-\pi^{*}$ \\
\hline
\end{tabular}

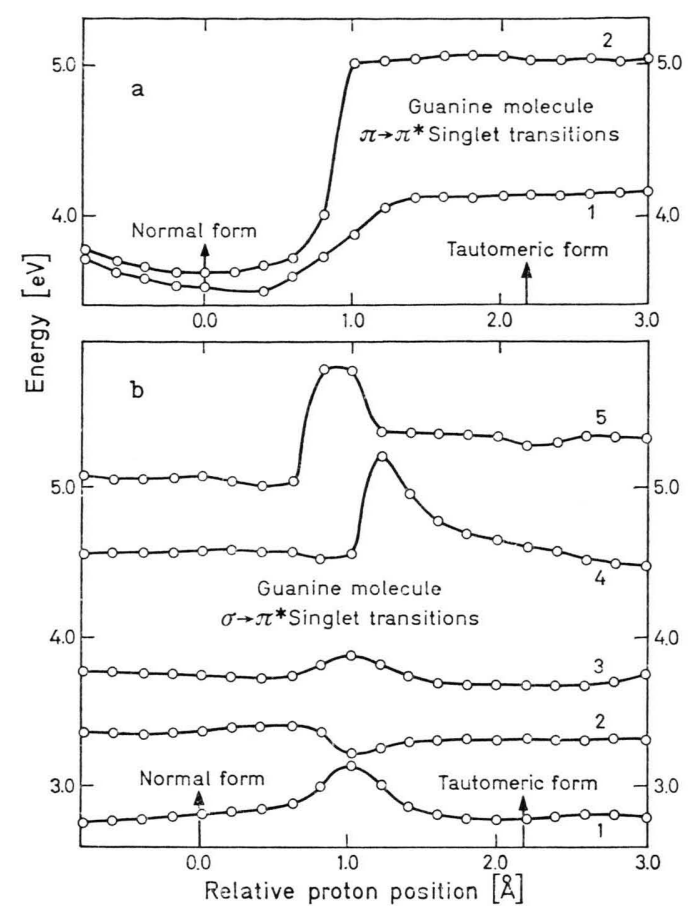

Fig. 2. a. Barrier for the motion of the H. Singlet $\pi-\pi^{*}$ transitions, molecule of guanine. b. Barrier for the motion of the H. Singlet $\sigma-\pi^{*}$ transitions, molecule of guanine.

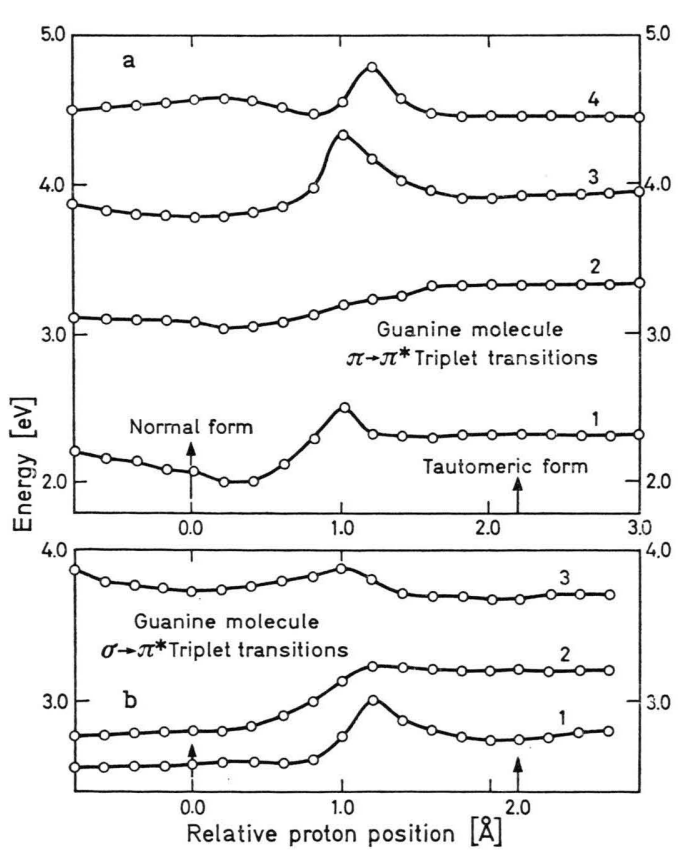

Fig. 3. a. Barrier for the motion of the H. Triplet $\pi-\pi^{*}$ transitions, molecule of guanine. b. Barrier for the motion of the H. Triplet $\sigma-\pi^{*}$ transitions, molecule of guanine. 


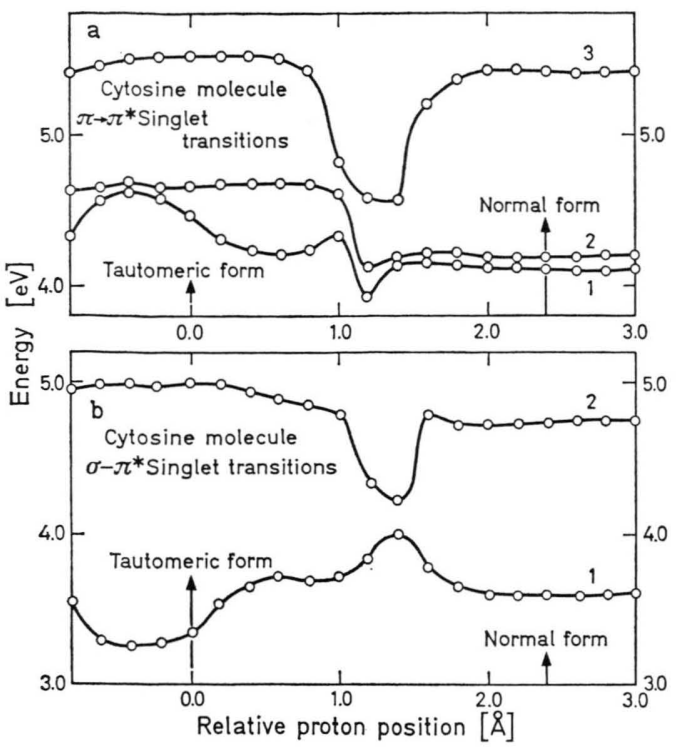

Fig. 4. a. Barrier for the motion of the H. Singlet $\pi-\pi^{*}$ transitions, molecule of cytosine. b. Barrier for the motion of the H. Singlet $\sigma-\pi^{*}$ transitions, molecule of cytosine.

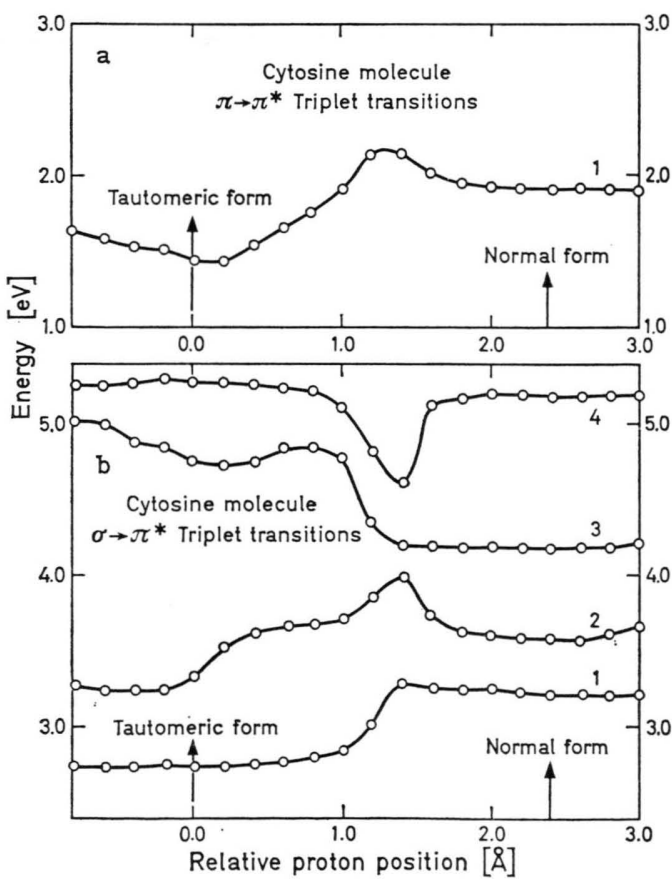

Fig. 5. a. Barrier for the motion of the H. Triplet $\pi-\pi^{*}$ transitions, molecule of cytosine. b. Barrier for the motion of the H. Triplet $\sigma-\pi^{*}$ transitions, molecule of cytosine. and $\pi-\pi^{*}$ singlet and triplet states are shown in Figs 2 and 3 .

For the normal molecule there is no trouble to determine the characteristic of the transition $\left(\sigma-\pi^{*}\right.$ or $\left.\pi-\pi^{*}\right)$, but some difficulties to assign the correlations of the levels arise with the movement of the $\mathrm{H}$ atom towards the tautomeric conformation (there is a mixture of configurations with different symmetries for some states). We have used the rules of Woodward-Hoffmann ${ }^{21}$ to overcome this problem in a way reported in a previous paper about the adenine and thymine bases ${ }^{19}$.

The calculations for the molecule of cytosine are quite similar, then we give up their discussion. The results are shown in Table II and Figs 4 and 5.

\section{Conclusions}

The calculated values should be compared with the available experimental data. These values are in the whole satisfactory, see Tables I b and II b for singlet and triplet states in both molecules.

Another results interesting to be attain are:

a) In both molecules there stables tautomeric forms for some excited states.

b) In general, there is more stability for the tautomeric form in the molecule of cytosine.

c) For both molecules the movement of the $\mathrm{H}$ atom between the normal and tautomeric conformers have an effect on the character and localization of the occupied levels involved in the observed optical transitions, see Tables I a and IIa. Anyway, the highest occupied m. o. are $\pi$ character in the normal and tautomeric conformer in both molecules (see Tables I a and II a), m. o. 28 and 21).

d) Morita ${ }^{16}$ has reported the existence of both conformers in solution. The result is in agreement with our conclusions a and $b$.

e) There is no excited triplet states for the tautomeric form in the range $3-4 \mathrm{eV}$ for the molecule of guanine (see Tables III a and b).

f) The stability of the tautomeric conformers in both molecules is directly concern with genetic errors in the duplication pattern of the cells assuming the schema given by Löwdin. For a more complete discussion see ${ }^{19}$.

We are grateful to Consejo Nacional de Investigaciones (CONICET) de Argentina and the Organizacion de Estados Americanos for their support during the development of this paper.

3 L. B. Clark and I. Tinoco, Jr., J. Amer. Chem. Soc. 87, 11 [1965].

4 J. Ladik and K. Appel, Theor. Chim. Acta 4, 132 [1966].
1 H. Berthod and A. Pullman, Biopolymers 2, 483 [1964]

2 H. Berthod, G. Giessner-Prettre, and A. Pullman, Theor. Chim. Acta 5, 53 [1966]. 
5 A. R. Katritzky and A. J. Waring, J. Chem. Soc. 1963, 3046.

6 C. Nagata, A. Imamura, Y. Tagashira, and M. Kodama, Bull. Chem. Soc. Japan 38, 1638 [1965].

7 R. F. Stewart and N. Davidson, J. Chem. Phys. 39, 255 [1963].

8 B. Mely and A. Pullman, Theor. Chim. Acta 13, 278 [1969].

9 A. Pullman and B. Pullman, Adv. Quantum Chem. 4, 267 [1968].

10 F. Jordan and H. D. Sostman, J. Amer. Chem. Soc. 95, 6544 [1972]

11 O. M. Sorarrain and E. A. Castro, Chem. Phys. Letters 19, 422 [1973].

12 R. Bonnaccorsi, E. Scrocco, J. Tomasi and A. Pullman, Theor. Chim. Acta 36, 339 [1975].
13 H. Miles, Biochim. Biophys. Acta 22, 46 [1958].

14 E. M. Tanner, Spectrochim. Acta 8, 9 [1956].

15 I. Wempln and J. J. Fox, J. Amer. Chem. Soc. 86, 2474 [1964].

16 H. Morita and S. Nagakura, Theor. Chim. Acta 11, 279 [1968].

17 A. Denis and M. Gilbert, Theor. Chim. Acta 11, 31 [1968].

18 J. D. Goddard, P. G. Mezey, and I. G. Csizmandia, Theor. Chim. Acta 39, 1 [1975].

19 J. Marañon and O. M. Sorarrain, to be published.

20 L. E. Sutton, Tables of interatomic distances and configurations in molecules and ions, The Chemical Society, London 1965.

21 N. Trong Anh., Las reglas de Woodward-Hoffmann, Editorial Reverté, Barcelona 1974. 